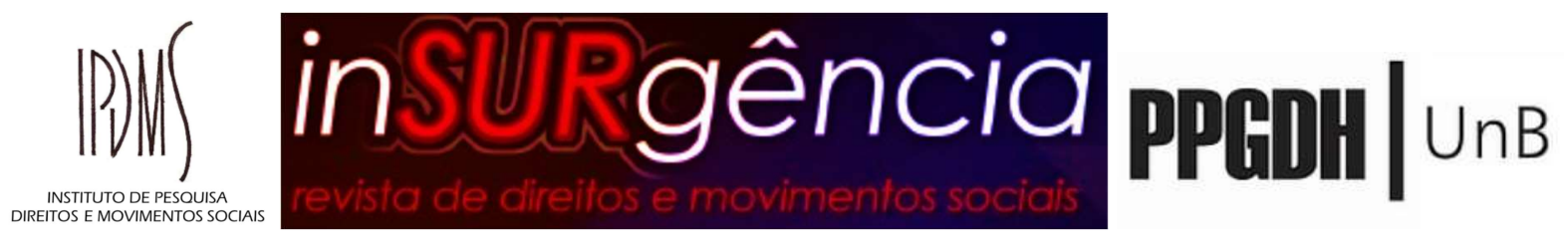

\title{
O ORDENAMENTO JURÍDICO BRASILEIRO E A POSSIBILIDADE DE ACEITAÇÃO DE UMA JUSTIÇA INDÍGENA AUTÔNOMA
}

\author{
BRAZILIAN LEGAL ORDER AND THE POSSIBILITY OF ACCEPTANCE OF AN \\ AUTONOMOUS INDIGENOUS JUSTICE
}

Rodrigo de Medeiros Silva Roberto Antonio Liebgott ${ }^{2}$

Resumo: O Movimento Indígena, suas organizações e organizações parceiras já discutem, politicamente, privilegiarem espaço de solução de conflitos próprios dos povos originários, em vez de se recorrer ao Poder Judiciário. Este, institucionalizado por uma cultura diversa, não saberia lidar a contento de suas demandas. Além disto, verifica-se uma carga preconceituosa na formação de muitos de seus membros que também prejudicariam os indígenas. Assim, inspirados nos estados plurinacionais da Bolívia e do Equador, propugna-se por um espaço legítimo de atuação jurisdicional, reconhecido pelo ordenamento jurídico posto. Para exemplificar modos próprios de solução de conflitos, descreve-se como se dá com os mbya guarani e Kaingang do Estado do Rio Grande do Sul.

Palavras-chave: Indígenas; Autonomia Judiciária; Justiça Comunitária; Pluralismo; Direitos Humanos.

\footnotetext{
Abstract: The Indigenous Movement, its organizations and partner organizations already discuss, politically, to privilege space for the resolution of conflicts inherent to the original peoples, instead of resorting to the Judiciary. This, institutionalized by a diverse culture, would not know how to cope with its demands. In addition, there is a biased burden on the formation

${ }^{1}$ Doutorando em Direito e Sociedade na Universidade La Salle, Mestre em Direitos Humanos pela UniRitter, Porto Alegre/RS (2019); graduou-se em Direito pela Universidade de Fortaleza-UNIFOR, Fortaleza/CE (2003); e é especialista em Direito Civil e Processual Civil, pelo Instituto de Desenvolvimento Cultural - IDC, em Porto Alegre-RS (2016). Participa da Rede Nacional de Advogadas e Advogados Populares-RENAP, Fórum Justiça, Articulação Justiça e Direitos Humanos- JusDH e do Coletivo de Advogados Ambientalistas do Rio Grande do Sul.

2 Possui graduação em Filosofia pela Faculdade de Filosofia Nossa Senhora Imaculada Conceição (1989) . Atualmente é Missionário do Conselho Indigenista Missionário. Tem experiência na área de Filosofia.
} 


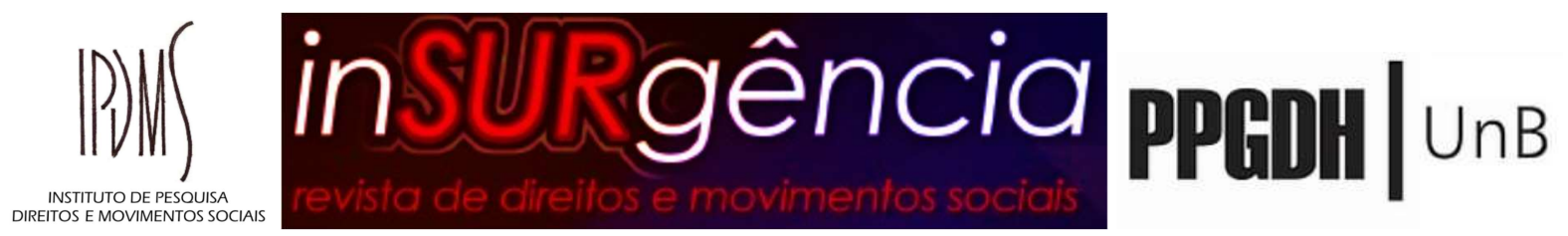

of many of its members that would also harm the indigenous. Thus, inspired by the plurinational states of Bolivia and Ecuador, it advocates for a legitimate space for judicial action, recognized by the legal system. To exemplify proper ways of conflict resolution, it is described as occurs with the mbya guarani and Kaingang of the state of Rio Grande do Sul.

Keywords: Indigenous; Judicial Autonomy; Community Justice; Pluralism; Human rights.

\section{INTRODUÇÃO}

O Brasil foi um país que sofreu uma colonização europeia e transplantou um modelo de sociedade europeu ${ }^{3}$, com instituições e normas inspiradas na Europa Ocidental e Estados Unidos. Sem negar que tenha havido formulações próprias, a partir da realidade local, é inegável esta incidência predominante de uma cultura formal, que desprivilegiou elementos do modo de ser dos povos africanos e indígenas.

Hoje o Brasil, apesar de todo genocídio cometido e ainda perpetrado contra os povos indígenas, existe 305 etnias (IBGE, 2019, s/p). Muitas destas sofreram o impacto da colonização e posterior política de integração violadora, que visara anular o modo de vida diversa, levando a uma padronização de comportamento, a um modelo de cidadania idealizado, não condizente com os projetos de vida, a existência que possuíam a priori. Isto levou a imposição de institutos e instituições do Estado brasileiro, permeado por uma cultura ocidental, que exclui o diverso e busca impor um modo de ser pautado pelo mercado e o consumo, a serviço de uma acumulação de bens e renda de determinados segmentos.

Está se formando um consenso político entre alguns espaços e referências indígenas de procurarem solucionar seus conflitos, sem precisar ou melhor, evitando o Poder Judiciário. Justifica-se, dada a compreensão que possuem do distanciamento do Judiciário da realidade e costumes de suas comunidades, bem como uma visão preconceituosa e estigmatizante que certos membros daquela instituição externaram em suas sentenças. Afinal, o pensamento

\footnotetext{
${ }^{3}$ A utilização do termo europeu será dentro dos parâmetros da crítica decolonial, sobre uma maneira de ser e organizar-se, quem nem sempre coincide com a localização geográfica: “As expressões 'europeu' e 'eurocentrismo' não estão atreladas ao aspecto geográfico, mas, possuem acepção política, o que nos remete a forma de dominação imperialista pautada nos ideias modernos. Assim como, o 'ocidente', pois, nem todos os países deste espaço geográfico representam a metódica colonialista, em absoluto. Por exemplo, nesses termos são países aderentes dessa concepção de mundo, a Nova Zelândia e Austrália, bem como ausentes dela, Cuba e Jmaica." (ROMANGUERA, TEIXEIRA, BRAGATO, 2005, p. 6)
} 


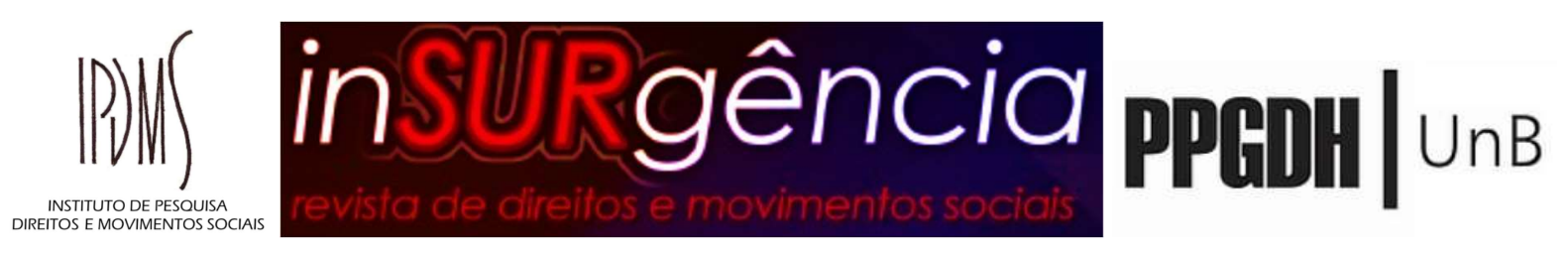

jurídico latino-americano está ligado a produção intelectual europeia, subordinada aquela. Sendo o conhecimento do colonizador, faz parte da dinâmica imperialista (CÁRDENAS, p. 56)

Este artigo, então, verificará se este posicionamento de autonomia de uma justiça comunitária indígena poderia ser aceito pelo atual ordenamento jurídico do país, sem sofrer modificações, mas se interpretando a Constituição Federal de forma a possibilitar tal mister. Para tanto, defende-se que o rol dos órgãos do Poder Judiciário, elencados no artigo 92 da Constituição Federal não seja taxativo. O Professor Dr. Luís Alberto Reichelt, em debate ocorrido no Ministério Público Federal da $4^{\text {a }}$ Região, ao ser indagado sobre a possibilidade de uma justiça autônoma dos indígenas brasileiros, afirmou que, em tese, se poderia seguir este caminho de legitimação (SILVA, 2019, s/p).

A defesa desta possibilidade, sem prejuízo do debate técnico-jurídico, irá para além da dogmática. Fundamentará também tal possibilidade na crítica decolonial à sociedade brasileira, propondo uma construção inclusiva do diverso. Calcar-se-á, então, na teoria do pluralismo jurídico, como uma forma, inclusive, de atender a fundamentos e objetivos dispostos na Constituição Federal.

Ao final, para demonstrar que isto é possível, ao afirmar que comunidades indígenas já assim funcionam, prescindindo dos atuais órgãos judiciários brasileiros, descreve-se formas de solução de conflitos de dois povos do Sul do país, quais sejam, os mbya guarani e Kaingang. Fica claro que negar a jurisdição indígena é negar a realidade, é se perder numa abstração que desrespeita as suas existências, o seus modos de ser.

\section{O DISTANCIMENTO DO PODER JUDICIÁRIO COMO CRÍTICA FUNDAMENTE DE UMA JUSTIÇA INDÍGENA COMUNITÁRIA.}

O ordenamento jurídico brasileiro sempre exortou a uma integração dos povos indígenas a um idealizado padrão de cidadania, que seria brasileiro. Inclusive, sempre viu os indígenas como mão de obra barata ou escrava para seus empreendimentos, sem considerar as aspirações destes sujeitos. Esta compreensão pode ser percebida desde as guerras justas, implantadas no período colonial: 


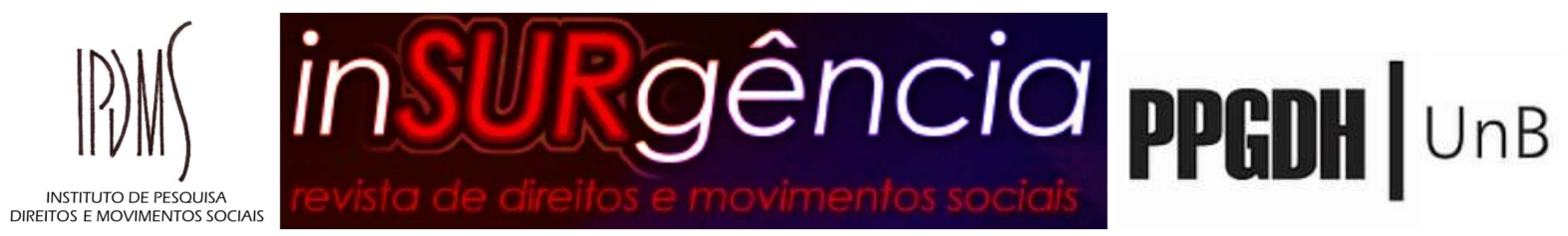

do governo real foi criar estradas e garantir o transporte por rios navegáveis, como o Doce e Pomba, incentivando a criação de presídios (espécies de quartéis nos quais se arregimentavam soldados, um lugar de guarda-limite contra os índios) nessas regiões, fornecendo subsídios a camponeses que habitassem essas áreas, com o claro objetivo de levar a fronteira da civilização mais adiante (SILVA, 2010, 365).

Não é à toa que o primeiro órgão indigenista da República se denominava Serviço de Proteção aos Índios e Localização dos Trabalhadores Nacionais (SPLTN), criado pelo Decreto $n^{\circ}$ 8.072/1010. A visão "integradora” só foi rompida com a Constituição Federal de 1988, mas não foi suficiente para se estabelecer o respeito ao diverso, de forma predominante, possuindo ainda inúmeros defensores na sociedade e instituições da imposição de um padrão de existência.

As duas primeiras constituições do país, a do Império (1824) e a primeira da República (1891), não possuíam nenhuma referência aos indígenas. A Carta de 1934 estabelecia que competia à União legislar sobre a incorporação dos silvícolas à comunhão nacional (artigo $5^{\circ}$, XIX, m). Importante entender que esta comunhão significaria abandonar o que era diverso, o modo de vida que lhes fossem característicos, que os definissem como um povo, para serem integrados ao que se entendia ser o "povo brasileiro". A Constituição de 1937 não reproduzia este dispositivo, mas a de $1946 \mathrm{sim}$ (artigo, XV, r). A de 1967 também (artigo 8, XVII, o) e a Emenda de 1969 também trazia tal conteúdo.

Em relação a legislação infraconstitucional, anterior a Constituição de 1988, o Código Civil de 1916 limitava a cidadania, a participação social dos indígenas, quanto mais fosse seu modo de vida diferenciado com o desejado pela elite do país. A época chamados de "silvícolas", eram considerados relativamente incapazes (artigo $6^{\circ}$ ). Eles seriam tutelados e isto só seria superado se adaptados (artigo $6^{\circ}$, §único), que significava abandonar seu modo de ser.

O Estatuto do Índio de 1973 traz um texto por vezes contraditório entre respeitar a cultura e integrar a um modo de vida diversa. Logo em seu artigo $1^{\circ}$ diz que o propósito desta Lei é de preserva a cultura e integrá-los, progressiva e harmoniosamente, à comunhão nacional. Fala em respeito aos valores culturais, tradições, usos e costumes no processo de integração (artigo $2^{\circ}, \mathrm{VI}$ ). Entretanto, também possui uma tônica em propiciar desenvolvimento e progresso. Mas estas expressões de uma caminhada linear ocidental são incompatíveis com as cosmovisões ameríndias. E fica o questionamento se a integração a nação brasileira, não seria a negação de outras nacionalidades, quais sejam, guarani, kaingang, krenak, tupinambá, tuxá, krenak, tremembé, kariri, waimiri-atroari, dentre outras.

Este caminho exortado pelo ordenamento é reflexo de uma compreensão que o desenvolvimento, o progresso seria chegar à nacionalidade brasileira. Isto demonstra uma 


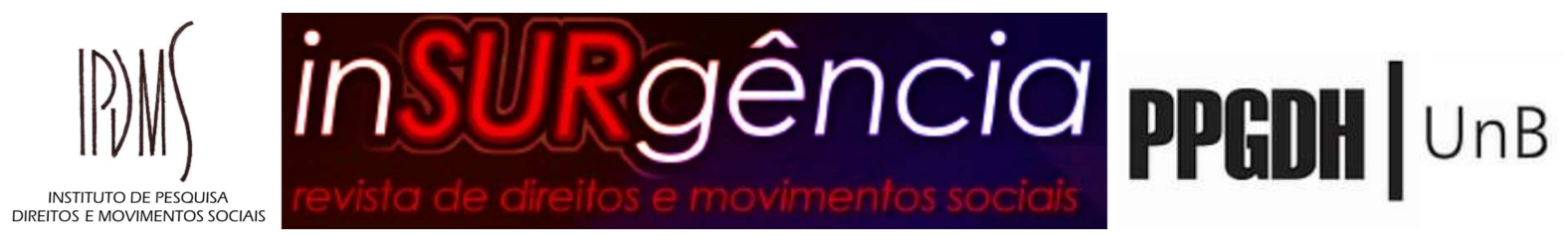

hierarquização entre os modos de vida e um entendimento de menor consideração dos valores diferenciados dos povos indígenas se comparados aos do Norte Global. É o que Anibal Quijano indica como colonialidade do poder, a imposição de uma classificação racial/étnica da população do mundo como pedra angular do referido padrão de poder (2010, p.84) O pensamento colonial permeia as instituições que se entendem de uma razão, de uma nação para qual as demais devem caminhar.

O quadro de desconsideração de bens e valores, de racionalidades diversas, ou de uma hierarquização dentre elas traz uma insatisfação. Assim, que o Movimento Indígena e as organizações e ele ligadas exortam por meios de solução de conflitos próprios que não os institucionalizados pelo pensamento do colonizador/invasor. A fala do atual chefe de Estado brasileiro, de que "o índio quer ser como nós" (ISTOÉ, 2018, s/p), comprova que as instituições brasileiras ainda não superaram a perspectiva colonizadora. Tal postura não dialoga com quem quer manter seu modo de vida diferenciado e, muito menos, com o direito de assim ser:

Hoje, os brancos acham que deveríamos imitá-los em tudo. Mas não é o que queremos. Eu aprendi a conhecer os seus costumes desde a minha infância e falo um pouco a sua língua. Mas não quero de modo algum ser um deles. (KOPENAWA e ALBERT, 2015, p. 75)

O Judiciário brasileiro, inserido nesta realidade de pensamento colonizado, possui muitos de seus membros com concepções de mundo similares ao do atual Poder Executivo:

Defender que cachorros comam índios é mera liberdade de expressão, diz TRF4

$[\ldots]$

O caso ocorreu em abril de 2013, quando uma das páginas da rede social veiculou fotografia de faixa com a seguinte inscrição: "Ou o Brasil acaba com a Funai ou a Funai acaba com o Brasil'". A mensagem fazia alusão à presença de indígenas na região de Guaíra e Terra Roxa, no Paraná. O homem decidiu completar a frase com a seguinte declaração: “'Ou ensinar nossos cachorros a comer 'indio', em vez de ração, um a cada dois dias já tá bom!!!!kkkkkkkk'.

(MARTINS, 2018, s/p)

O que se propõe é a possibilidade do reconhecimento de instituições judiciárias diversas, compatíveis com a cultura de cada povo indígena do território brasileiro. Ter-se-ia como referencial justiça comunitária:

Justiça comunitária significa um conjunto de instâncias e procedimentos através que, em situações controversas, comportamentos legítimos são regulados para das normas de uma comunidade ou contexto cultural específico. É administração da justiça da 


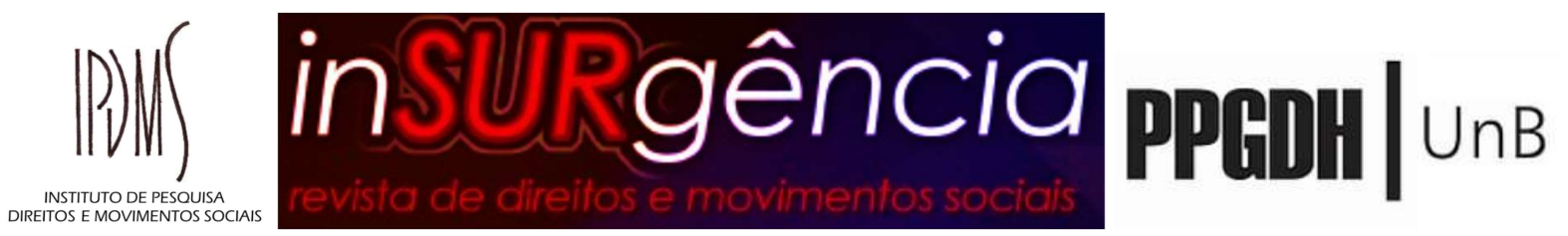

comunidade, com base em suas próprias regras e princípios. É a administração da justiça à medida que se desenvolve no campo da regulação social: atua sobre referências normativas que a precedem e produz mandatos em conflitos específicos. É comunidade, desde que sua capacidade reguladora provenha de identidade e pertencimento ao mesmo. Esse sentimento pode ser causado por afetos ou tradição (AMAYA, 2010, p. 3). (tradução livre)

Faz-se necessário um respeito às relações concretas, as pessoas e suas condições reais para que se alcance a justiça, superando abstrações como "paz social" e "segurança jurídica". O termo pacificação é sempre utilizado para dominação, violação e não para se dirimir o conflito levando em conta a equidade, os anseios, perspectivas e direitos. Assim, as intervenções judiciais diminuiriam as chances de serem consideradas inoportunas e impertinentes (AMAYA, 2016, p. 494)

\section{A POSSIBILIDADE DE PLURALIDADE DE JURISDIÇÕES NO ATUAL ORDENAMENTO JURÍDICO BRASILEIRO PARA CONSECUÇÃO DE JUSTIÇA SOCIAL NO INTERIOR DAS COMUNIDADES INDÍGENAS}

A tradição monista da cultura jurídica brasileira, que segue um sistema lógico-formal com centralismo estatal não consegue apreciar a contento conflitos coletivos de dimensão social (WOLKMER, 2015, p. 103). Além disto, fazendo parte de uma cultura latino-americana, ela importa instituições e normas jurídicas, sem estudar primeiro a realidade onde serão aplicadas; possui um fetichismo legal; instrumentaliza o judiciário para questões políticas; e reproduz dogmas do formalismo europeu (CÁRDENAS, p. 57).

Defende-se, então, a concepção pluralista de cultura jurídica, que albergue diversas formas e espaços, a partir de conhecimentos e valores diferentes, sem dependência, hierarquização. Entende-se por pluralismo jurídico:

[...] a multiplicidade de manifestações e práticas normativas existentes num espaço sociopolítico, interagidas por conflitos ou consensos, podendo ser ou não oficiais e tendo sua razão de ser nas necessidades existenciais, materiais e culturais (WOLKMER, 2015, p. 257).

Reconhece-se que o ordenamento jurídico brasileiro não foi pensando e instituído para ter esta amplitude. Contudo, não significa que não se possa utilizar interpretações que comportem tal concepção, que irá depender das forças políticas e conformações sociais que se dê no país. Mas é certo que o preâmbulo da Constituição Federal se coloca que se quer instituir 


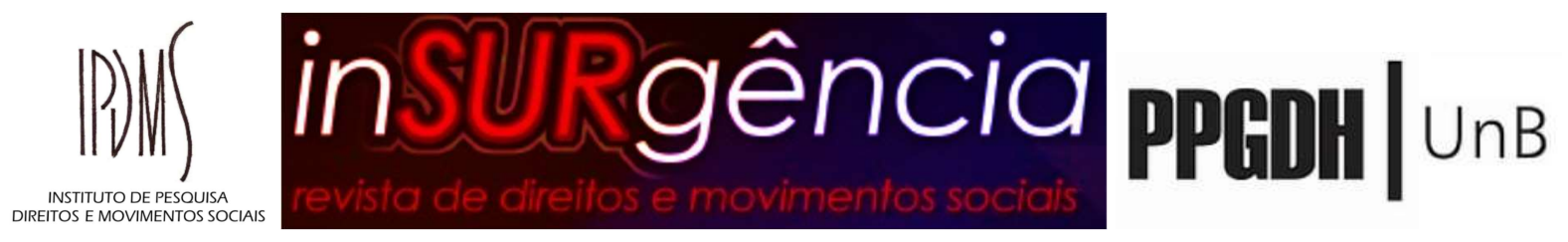

um Estado Democrático de Direito que possua, dentre outras características, uma sociedade pluralista e sem preconceitos. Estabelece também como fundamento do Estado brasileiro o pluralismo político (artigo $1^{\circ}, \mathrm{V}$ ), condição necessária para se constituir o pluralismo jurídico. Afinal, o que aqui se propõe é não negar a existência de mais de uma realidade, a diversidade de campos sociais com particularidades próprias, uma diversidade de interesses e valores, que quebram com o monismo social (WOLKMER, 2015, p. 185 e 186)

Partindo destes pressupostos que, então, irá se defender que o dispositivo constitucional, o qual diz quais os órgãos do Poder Judiciário, é exemplificativo e não taxativo (artigo 92). Assim, poderia se estabelecer o respeito por uma justiça comunitária indígena ou melhor, justiças, no plural, por se tratar de inúmeros povos. A apreciação pelo Poder Judiciário é um direito fundamental (artigo $5^{\circ}, \mathrm{XXXV}$ ), mas qual órgão deste Poder, de que forma atua e parâmetros que segue, pode ter uma margem de ampliação. Isto, porque os direitos e garantias expressos na Constituição não excluem outros decorrentes do regime e dos princípios por ela adotados, ou dos tratados internacionais adotados pelo país (artigo $5^{\circ}, \S 2^{\circ}$, da CF). O que se afirma aqui é que o pluralismo jurídico estabelecido por justiça indígena autônoma seria uma maneira de realizar os direitos destes povos insculpidos na própria Carta Magna:

Art. 231. São reconhecidos aos índios sua organização social, costumes, línguas, crenças e tradições, e os direitos originários sobre as terras que tradicionalmente ocupam, competindo à União demarcá-las, proteger e fazer respeitar todos os seus bens.

$\S 1^{\circ}$ São terras tradicionalmente ocupadas pelos índios as por eles habitadas em caráter permanente, as utilizadas para suas atividades produtivas, as imprescindíveis à preservação dos recursos ambientais necessários a seu bem-estar e as necessárias a sua reprodução física e cultural, segundo seus usos, costumes e tradições.

$\S 2^{\circ}$ As terras tradicionalmente ocupadas pelos índios destinam-se a sua posse permanente, cabendo-lhes o usufruto exclusivo das riquezas do solo, dos rios e dos lagos nelas existentes.

$\S 3^{\circ} \mathrm{O}$ aproveitamento dos recursos hídricos, incluídos os potenciais energéticos, a pesquisa e a lavra das riquezas minerais em terras indígenas só podem ser efetivados com autorização do Congresso Nacional, ouvidas as comunidades afetadas, ficandolhes assegurada participação nos resultados da lavra, na forma da lei.

$\S 4^{\circ}$ As terras de que trata este artigo são inalienáveis e indisponíveis, e os direitos sobre elas, imprescritíveis.

$\S 5^{\circ}$ É vedada a remoção dos grupos indígenas de suas terras, salvo, "ad referendum" do Congresso Nacional, em caso de catástrofe ou epidemia que ponha em risco sua população, ou no interesse da soberania do País, após deliberação do Congresso Nacional, garantido, em qualquer hipótese, o retorno imediato logo que cesse o risco. 


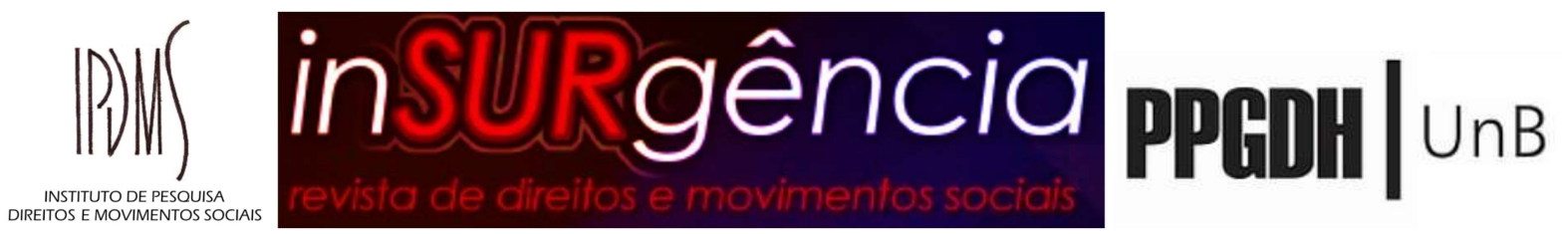

$\S 6^{\circ}$ São nulos e extintos, não produzindo efeitos jurídicos, os atos que tenham por objeto a ocupação, o domínio e a posse das terras a que se refere este artigo, ou a exploração das riquezas naturais do solo, dos rios e dos lagos nelas existentes, ressalvado relevante interesse público da União, segundo o que dispuser lei complementar, não gerando a nulidade e a extinção direito a indenização ou a ações contra a União, salvo, na forma da lei, quanto às benfeitorias derivadas da ocupação de boa fé.

$\S 7^{\circ}$ Não se aplica às terras indígenas o disposto no art. $174, \S 3^{\circ}$ e $\S 4^{\circ}$.

Art. 232. Os índios, suas comunidades e organizações são partes legítimas para ingressar em juízo em defesa de seus direitos e interesses, intervindo o Ministério Público em todos os atos do processo.

Outro fundamento para adoção da justiça indígena poderia ser reconhecido no artigo $2^{\mathrm{a}}$ da Convenção $n^{\circ} 169$ da OIT, internalizado via Decreto $n^{0}$ 5.051/2004. Ele determina, dentre outras coisas, que se adote medidas que promovam a plena efetividade dos direitos sociais, econômicos e culturais desses povos, respeitando a sua identidade social e cultural, os seus costumes e tradições, e as suas instituições. Os povos originários têm ou tinham seus meios de soluções de conflitos, que pelo processo violador de colonização e de transplante cultural, foram desconsiderados, negados ou proibidos. Agora, se propõe a reabilitação dos mesmos e o reconhecimento que a justiça comunitária indígena é uma instituição legítima.

Da mesma forma, a previsão de autonomia e autogoverno prevista pela Declaração das Nações Unidas sobre os Direitos dos Povos Indígenas (artigos $3^{\circ}$ e $4^{\mathrm{a}}$ ), pode ser lembrada para justificar a adoção de tal interpretação extensiva sobre o artigo 92, da CF. Esta Declaração vai mais além, colocando expressamente que os povos indígenas possuem o direito de conservar e reforçar suas instituições jurídicas (artigo $5^{\circ}$ ). Ela deve ser aplicada no Brasil, haja vista o país já ter tomado posicionamento favorável a mesma, sem necessidade de uma norma interna para tanto, pois como visto acima, a Constituição Federal (artigo $5^{\circ}, \S 2^{\circ}$ ) já incorpora automaticamente (UNESCO, 2008, p. 9).

A livre determinação também está disposta na Declaração Americana sobre os Povos Indígenas (artigo III). E da mesma forma que a declaração do Sistema ONU determina que os Estados devem reconhecer os sistemas e instituições jurídicas próprias (artigo VI). Tratando-se de norma de direitos humanos, da mesma forma que a discutida anteriormente, incorpora-se ao ordenamento brasileiro por força de determinação constitucional (artigo $5^{\circ}, \S 2$ ). Destacando que o Brasil participou ativamente de sua aprovação (FUNAI, 2016, s/p).

Não é novidade tal aceitação para cultura institucional sul-americana. As Constituições da Bolívia e do Equador já dão este reconhecimento. A Carta Equatoriana prevê uma Justiça 


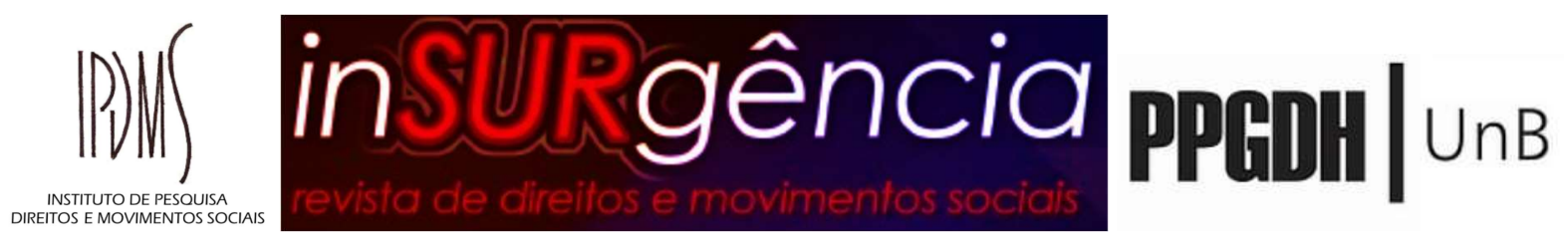

Indígena (artigo 171). A Boliviana diz que o Estado garantirá uma justiça plural (artigo 115), bem como um Tribunal Constitucional Plurinacional (artigo 158), sustentado pelos princípios do pluralismo jurídico e da interculturalidade, dentre outros (artigo 178). Ainda estabelece uma jurisdição indígena originária campesina (artigos 190, 191 e 192) com a mesma hierarquia dos demais órgão jurisdicionais, submetendo-se à justiça constitucional do Tribunal Constitucional Plurinacional (artigo 179):

A nova Constituição da Bolívia, de 2009, cria uma estrutura chamada de plurinacional, onde 36 etnias são reconhecidas como nações que, juntas, compõem o Estado Plurinacional da Bolívia. O próprio Tribunal Constitucional passou a ter uma composição mista, que representa as nações indígenas, assim como outras estruturas estatais.

Ainda que a nova constituição já previsse a existência da Justiça Indígena Campesina, bem como sua coexistência com a Justiça Ordinária, o Tribunal Constitucional Plurinacional, em decisão inédita, trouxe um novo entendimento quanto a dimensão da atuação dessa justiça ancestral, hoje reconhecida pelo estado.

O Tribunal, ao decidir uma questão de competência, utilizou como critérios informações culturais e antropológicas, com base em dados estatísticos e estudos realizados pela Unidade de Descolonização do Tribunal Constitucional Plurinacional, que, por meio de nota técnica, demonstra a origem étnica e formação cultural da população de Poroma.

Além de dirimir conflito de competência entre a Justiça Comum e a Justiça Indígena Campesina por critérios culturais antropológicos, estabeleceu a coexistência de bases jurídicas distintas, de cada nação indígena e a ordinária, onde não há hierarquia entre elas, para em conjunto formar um modelo de jurisdição multifacetado que respeita a formação histórica de cada povo e ao mesmo tempo estabelece limites, tendo em vista os direitos humanos, tratados internacionais e garantias constitucionais.

(STF, 2012, s/p)

Observe-se que os critérios utilizados para a existência da Indígena Campesina e a coexistência com a Justiça Ordinária e o Tribunal Constitucional Plurinacional também são encontrados no ordenamento brasileiro, quais sejam, culturais e antropológicos. Leva-se em conta também os direitos humanos dispostos nos tratados internacionais e nas garantias constitucionais. Como demonstrado acima, a Constituição Brasileira reconhece aos indígenas organização social, costumes, línguas, crenças e tradições (artigo 231). Pode-se perfeitamente incluir a jurisdição própria à organização social, costumes e tradições.

Sobre interpretar de forma não taxativa o artigo 92, da Constituição Federal, basta observar o artigo $5^{\circ}, \S 2^{\circ}$, que determina que direitos e garantias expressos nesta Constituição não excluem outros decorrentes do regime e dos princípios por ela adotados, ou dos tratados internacionais em que a República Federativa do Brasil seja parte. Então, observando o que estabelece a Convenção ${ }^{0} 169$ da OIT, a Declaração das Nações Unidas sobre os Direitos dos Povos Indígenas e a Declaração Americana sobre os Povos Indígenas, não se teria alternativa 


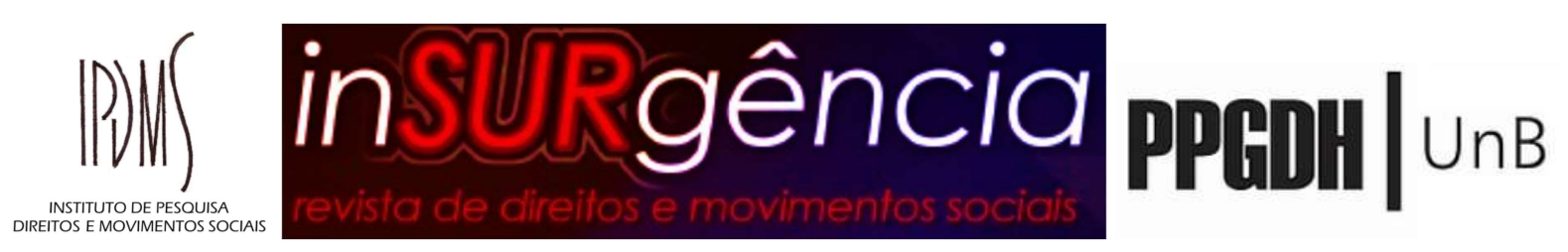

se não legitimar a jurisdição própria dos povos originários. Estes três documentos internacionais estabelecem o respeito aos usos e costumes, as tradições e instituições. Sendo que os dois últimos são mais expressos, específicos e não deixam dúvida que se deve conservar e reforçar as instituições jurídicas destas comunidades. Assim, se elas possuem seus meios próprios de resolução de conflitos, não há que se obrigar a submissão a uma jurisdição que não compreende, não contempla de forma satisfatória suas demandas.

Isto faria com que o termo "plural", disposto no texto constitucional ganhasse eficácia. A aceitação de jurisdições indígenas, específicas de cada povo que a tenha como de sua tradição, daria sentido ao pluralismo disposto no preâmbulo no artigo $1^{\circ}, \mathrm{V}$, da CF. Iria além do aspecto político e realizaria os bens jurídicos dispostos nos artigos 231 e 232, da CF.

\section{NA DIVERSIDADE DE POVOS E CULTURAS POVOS INDIGENAS PODEM NOS AJUDAR A IMPLANTAR O PLURALISMO JURIDICO}

Vivem atualmente no Brasil 305 povos indígenas, que se diferenciam étnica e culturalmente entre si. Além destes, que são reconhecidos pelo estado e suas instituições, existem mais de uma centena de povos ou comunidades que vivem em situação de isolamento voluntário ou, como refere o Conselho Indigenista Missionário, são os povos livres. A opção por não se estabelecer nenhum contato com a sociedade envolvente é deles.

A diversidade étnica em nosso país impressiona, porque além das realidades de povos de aldeias, em terras demarcadas ou não, ou aqueles em isolamento, há ainda milhares de pessoas - segundo o IBGE são quase a metade da população indígena brasileira - vivendo em comunidades ou de forma dispersa nas cidades. Estas pessoas ou população passaram a ser denominadas de "indígenas nas cidades ou em contexto urbano". Habitam as capitais de estados como Porto Alegre, Manaus, São Paulo, Rio de Janeiro, Fortaleza e centenas de cidades pelo Brasil. Todos, quase sem exceção, mantém vínculos comunitários, culturais, tais como a língua, as crenças, as cosmologias, os hábitos alimentares e suas organizações sociais, políticas, culturais e o modo de ser e de se relacionar com a terra e com o meio ambiente onde se encontram.

Os povos indígenas são constantemente impactados pela ofensiva do Estado brasileiro, porque este busca impor suas regras jurídicas, o que pode provocar a descaracterização das suas práticas culturais e organizativas. Há ainda, da parte da sociedade envolvente, um certo 


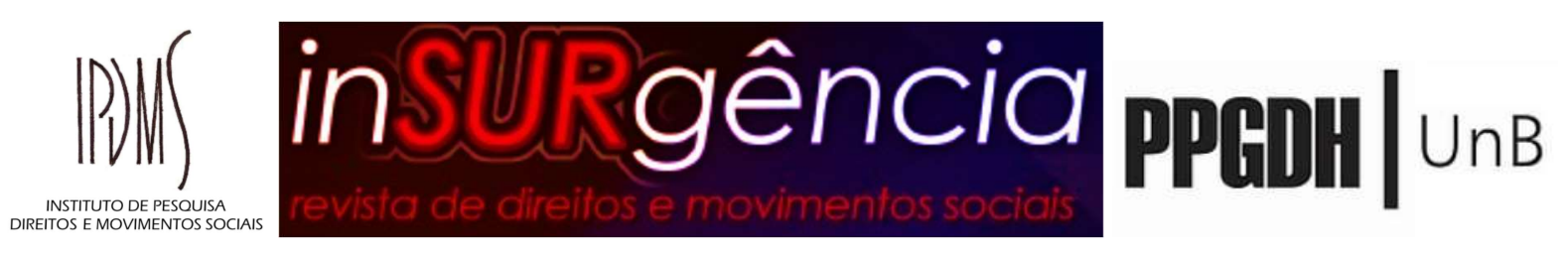

desconhecimento sobre as realidades indígenas no país e, paralelo a isso, existe uma relação de intolerância com o modo de ser dos indígenas. E, mais grave que isso, há uma negação aos direitos dos povos o que, em grande medida, ajuda na propagação das violências, sendo a principal delas a negação do direito à terra, que são avassaladoras. O estado, em síntese, sempre quer impor e fazer valer as regras do sistema jurídico dos não indígenas. Mas, apesar de toda pressão que sofrem, centenas de povos mantém estruturas internas que são verdadeiros sistemas de justiça e, por conseguinte, meios para se fazer a resolução de conflitos e com os quais poderia se aprender.

Nesta reflexão sobre jurisdição indígena se torna oportuno tomar algumas proposições gerais indicadas por Shelton Davis (1973) e que são comuns nas maiorias das sociedades: a) nas sociedades existem um corpo de categorias culturais, de regras ou códigos que definem os direitos e deveres legais entre as pessoas; b) nas sociedades ocorrem disputas e conflitos quando as regras são rompidas; c) nas sociedades existem meios institucionalizados através dos quais os conflitos são resolvidos e através dos quais as regras internas são reafirmadas ou redefinidas.

No Brasil os povos indígenas, ao menos a sua grande maioria, não têm um código escrito, no entanto eles possuem normas que são transmitidas de geração para geração na forma oral. Elas existem desde muitas décadas, algumas ancestrais. No entanto, pela relação de proximidade ou de distanciamento com a sociedade envolvente, as regras vão se ajustando ou até se transformando. De todo modo, quando se nota que as regras são desrespeitadas internamente as comunidades buscam alternativas para a resolução de um conflito que se originou da quebra de regras culturais, mesmo daquelas que pareciam perenes. E quando uma regra é quebrada, aciona-se ou articula-se um sistema interno de resolução de conflitos. E geralmente, quando há necessidade de se encontrar uma solução são acionados a família, ou o clã, daquele diretamente envolvido, depois, em havendo necessidade de uma intervenção externa à família, convoca-se as lideranças comunitárias e o cacique. Não raras vezes é chamado o líder religioso, Pajé, que pode ser masculino ou feminino. Se, eventualmente o conflito não se dissolveu o Pajé, tenta o diálogo com todos os envolvidos. Essas formas organizativas seguem as lógicas de cada povo, alguns com mecanismos de solução de conflitos mais restritivo, ou seja, nem todos precisam participar e, em outros casos, a própria comunidade é chamada para ajudar a encontrar uma solução, inclusive na perspectiva de impor uma punição.

No Rio Grande do Sul convivem com a sociedade envolvente os povos kaingang, que tem uma população superior a 30 mil pessoas, os guarani, com população de 2 mil e 500 pessoas 


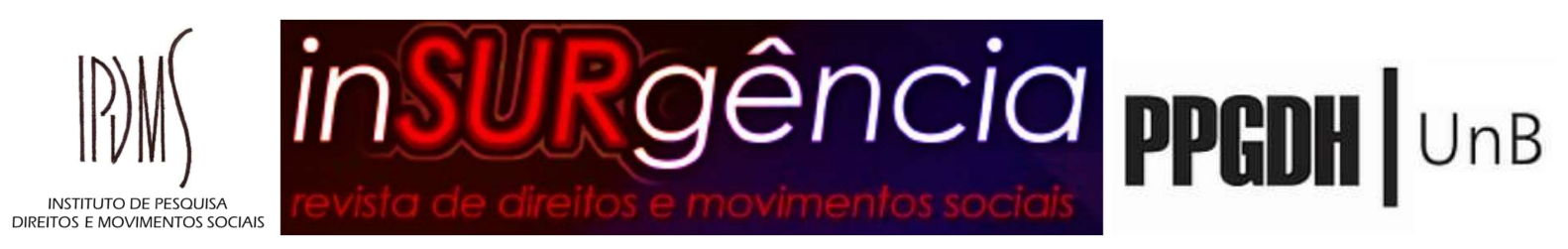

e Charrua com 70 pessoas. Cada um desses povos tem mecanismos culturais próprios para a solução de conflitos internos. No caso dos kaingang, quando há algum problema a busca por solução sempre envolve aquele quebrou uma determinada regra interna, sua família e o Cacique, geralmente eleito ou aclamado pela comunidade. No entanto, o cacique não administra sozinho a comunidade, ele identifica pessoas de sua confiança para formar um grupo de conselheiros que vão auxiliá-lo nas demandas internas. E nos casos de conflitos - brigas, desavenças e outros problemas - eles ajudam no diálogo tendo em vista uma solução do conflito e até mesmo na imposição de alguma sanção.

Os mbya guarani vivem, em geral, em pequenos grupos familiares. Todas as demandas são discutidas e resolvidas nestes espaços. Quando há fato grave e que coloca em risco a vida de pessoas, ou viola a cultura e o modo de ser Mbya, acionam-se regras de conteúdo espiritual. São, portanto, determinantes para a solução de um conflito o Karaí- o Pajé- ou a Kunhã Karaí - a Pajé-. Eles detêm os conhecimentos de todas aquelas regras determinadas por Nhanderu, regras sagradas e aquelas construídas no âmbito da cultura, das relações sociais. Geralmente são os líderes espirituais e os mais velhos que sabem o conselho a ser dado e qual restrição será imposta para aquele que eventualmente causou algum mal para uma pessoa ou para a coletividade.

Portanto, se a sociedade brasileira se propõe a um sistema de Justiça mais democrático, efetivo, justo e ágil não pode deixar de observar os modos de ser dos povos indígenas e aprender com eles. Dever-se-ía avançar para uma perspectiva de um sistema plural, onde se possa encontrar caminhos e soluções integrais, que efetivamente respondam as demandas e expectativas das sociedades, que hoje se fazem cada vez mais plurais, não tão somente as indígenas. Dialogar com os demais sistemas é fundamental no sentido de que se assegure, inclusive, o cumprimento de nossa Constituição Federal.

\section{CONCLUSÃO}

O transplante de instituições e institutos termina por criar dois modelos violadores, segundo Cárdenas (p. 73 e 75), um da ineficácia, pois não compatível com as demandas que enfrenta e os valores dos sujeitos envolvidos; e outro do autoritarismo, bem típico da violência e intransigência do pensamento colonizador, impondo algo que também não realizará a justiça 


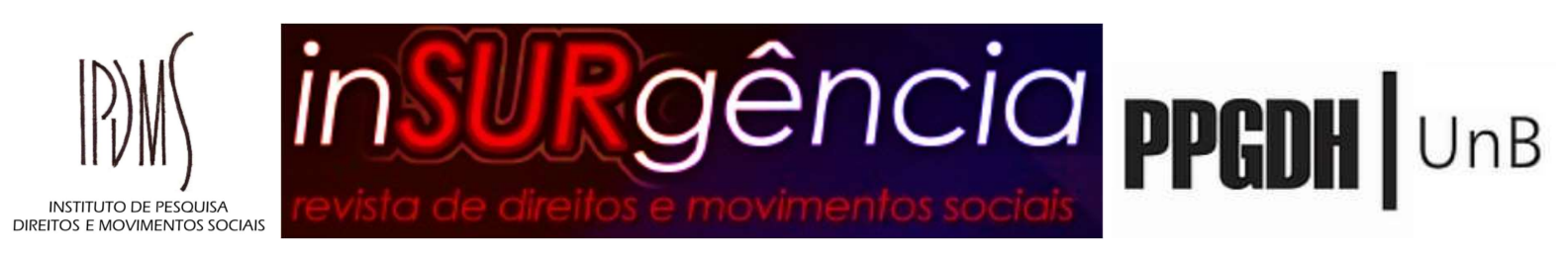

social, muito pelo contrário. Entender que os órgãos jurisdicionais brasileiros seriam apenas os exemplificados no artigo 92, da CF, causa repetitivamente violações a tradições, costumes e instituições de povos que possuem suas próprias formas de solução de conflitos.

A construção excludente da sociedade brasileira, que sempre impeliu estes povos a se "integrarem" de forma a se descaracterizarem, nunca permitiu uma jurisdição própria. Isto termina por ser mais uma violação, pois se possuem sua maneira específica de soluções conflito, por que não a respeitar, entendê-la como autônoma e não submissa a uma cultura jurídica alicerçada na negação de sua existência? Os ditames do pluralismo jurídico iriam trazer eficácia aos dispositivos constitucionais e infra que determinam observância aos usos e costumes, tradições e instituições jurídicas dos indígenas.

O pluralismo da sociedade e do Estado brasileiro (Preâmbulo e artigo $1^{\circ}, \mathrm{V}$, da CF) deixaria de ser uma abstração, neste aspecto, se a justiça comunitária indígena fosse considerada em patamar de igualdade com os demais órgãos jurisdicionais disposto na Constituição Federal. Isto não retiraria o controle constitucional do Supremo Tribunal Federal, mas sim o fortaleceria albergando a diversidade existente de fato no país.

A Constituição Federal é clara ao observar direitos e garantias para além dos nela expressos decorrentes do regime e dos princípios por ela adotados, ou dos tratados internacionais em que a República Federativa do Brasil seja parte (artigo $5^{\circ}, \S 2^{\circ}$ ). Foi, então, demonstrando no decorrer deste trabalho que tanto a Carta Magna (artigos 231 e 232), como a Convenção $n^{\circ} 169$ da OIT, a Declaração das Nações Unidas sobre os Direitos dos Povos Indígenas e a Declaração Americana sobre os Povos Indígenas determinam o respeito não só as tradições e usos e costumes, como também aos institutos jurídicos dos povos originários. $\mathrm{O}$ desafio se coloca em identificar se os mesmos possuem meios próprios de solução de conflitos, que poderiam ser entendidos como uma jurisdição. Isto comprovado, haveria de ser respeitada esta justiça autônoma.

O último tópico deste artigo apresentou um quadro geral sobre os indígenas brasileiros, até descrever um pouco meios de solução de duas etnias presentes no Rio Grande do Sul, os mbya guarani e os kaingang. Não se aprofundou nos fundamentos culturais de suas regras, na descrição de suas cosmovisões. Entretanto se demonstrou eu estas, como muitas outras no território brasileiro, possuem seus meios próprios de solução de conflitos. Se quer se dar efetividade a pluralidade disposta na Constituição, bem como os direitos destes povos 


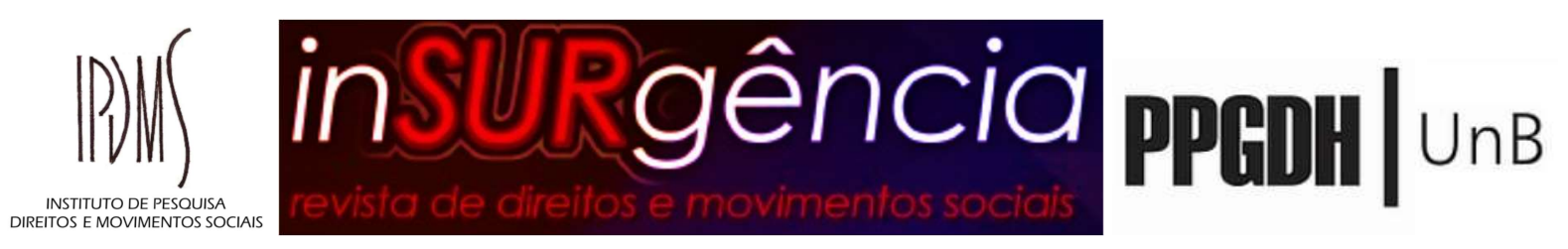

estabelecidos no ordenamento jurídico, haveria de se reconhecer uma jurisdição própria dos mesmos.

O modelo jurisdicional excludente de práticas e autoridades específicas destas populações não realiza justiça social, faz caminho inverso à construção de uma sociedade justa (artigo $3^{\circ}$, I, da CF). O monismo e formalismo a que Judiciário brasileiro encontra-se engessado promove preconceito, discriminação. O censo do Conselho Nacional de Justiça apresentou que $0,1 \%$ dos juízes se identificam como indígenas, sendo $84,5 \%$ auto-identificados como brancos (OLIVEIRA, 2014, s/p). Estes números demonstram que o Estado brasileiro ainda se comporta de forma colonial, submetendo os povos originários a uma cultura exógena, a instituições estranhas, não compatíveis com o respeito que figura nos dispositivos constantes no ordenamento jurídico. A pluralidade de órgãos jurisdicionais para a efetivação de uma justiça comunitária indígena fará com que o Brasil seja mais inclusivo.

\section{REFERÊNCIAS}

AMAYA, Edgar Augusto Ardila. De la Justicia Judicial a la Justicia Comunitaria. Tese de Doutorado. Madrid: Universidad Carlos III de Madrid, 2016.

Justicia Comunitaria y Sociedad Nacional. Publicado em: 2010. Disponível em:

https://www.academia.edu/38705957/Justicia_Comunitaria_y_Sociedad_Nacional?auto=dow nload. Acesso em: 27 nov 2019.

CÁRDENAS, Diego. Recepción de la cultura jurídica em latinoamerica. In: CÁRDENAS, Diego y outros. Aproximaciones a la Cultura Jurídica em Latinoamerica y Colombia. Bogotá: Universidad Nacionale Colombia, 2016, p. 49-82.

DAVIS, Shelton H. Antropologia do Direito. Rio de Janeiro, RJ: Zahar Editores, 1973.

FUNAI. OEA aprova Declaração Americana sobre os Direitos dos Povos Indígenas. Publicado em: 28 jun 2016. Disponível em: http://www.funai.gov.br/index.php/comunicacao/noticias/3815-oea. Acesso em: 27 nov 2019. IBGE. Estudos especiais. Disponível em: https://indigenas.ibge.gov.br/estudos-especiais3.html. Acesso em: 06 dez 2019. 


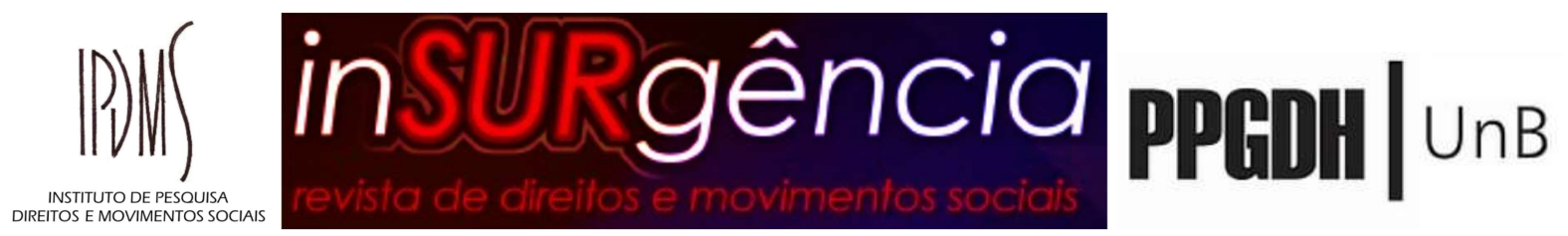

ISTOÉ. "Índio quer ser como nós", diz Bolsonaro ao comentar políticas ambientais. Publicado em: 14 nov 2018. Disponível em: https://istoe.com.br/bolsonaro-sem-problemasambientais-rr-tinha-tudo-para-ser-estado-mais-rico/. Acesso em: 06 dez 2019.

KOPENAWA, Davi; ALBERT, Bruce. A queda do céu: palavras de um xamã yanomami. 1 ed. São Paulo: Companhia das Letras, 2015.

MARTINS, Jomar. Defender que cachorros comam índios é mera liberdade de expressão, diz TRF-4. Publicado em: 01 abr 2018. Disponível em: https://www.conjur.com.br/2018-abr01/defender-caes-comam-indios-liberdade-expressao-trf. Acesso em: 06 dez 2019.

QUIJANO, Aníbal. Colonialidade do poder e classificação social. In: SANTOS, Boaventura de Sousa; MENESES, Maria Paula [orgs]. Epistemologias do sul. 1 ed. São Paulo: Cortez, 2010. ROMANGUERA, Daniel Carneiro Leão; TEIXEIRA, João Paulo Allain; BRGATO, Fernanda Frizzo. Por uma crítica descolonial da ideologia humanista dos direitos humanos. Derecho y Cambio Social. Publicado em: 01 out 2014. Disponível em: https://www.google.com.br/url?sa=t\&rct=j\&q=\&esrc=s\&source=web\&cd=1\&ved=2ahUKEw ¡MoPnQjYjmAhXILLkGHe2MD7AQFjAAegQIBBAC\&url=https\%3A\%2F\%2Fdialnet.uniri oja.es\%2Fdescarga\%2Farticulo\%2F5470223.pdf\&usg=AOvVaw311QUL82D1PsACZpfedik. Acesso em: 26 nov 2019.

SILVA, Rodrigo de Medeiros. Lançado o Edital da Revista Insurgência- Processo Civil \& Direitos Humanos. Disponível em: https://www.forumjustica.com.br/lancado-o-edital-darevista-insurencia-processo-civil-direitos-humanos/. Acesso em: 25 nov 2019.

SILVA, Thiago Henrique Mota. Guido Thomaz Marlière e os índios Botocudo nos sertões do Leste (1818-1824). Universidade Federal de Viçosa. Revista de C. Humanas, V. 10, No 2 , p. $361-375$, jul./dez. 2010.

STF. Tribunal Constitucional da Bolívia reconhece autonomia da Justiça Indígena. Publicado em: 2012. Disponível em: https://www2.stf.jus.br/portalStfInternacional/cms/destaquesNewsletter.php?sigla=newsletter PortalInternacionalDestaques\&idConteudo=241307. Acesso em: 27 nov 2019.

UNESCO. Declaração das Nações Unidas sobre os Direitos dos Povos Indígenas: perguntas e respostas. Publicado em: 2008. Disponível em: https://unesdoc.unesco.org/ark:/48223/pf0000162708. Acesso em: 27 nov 2019.

WOLKMER, Antonio Carlos. Pluralismo Jurídico: fundamentos de uma nova cultura do direito. 4 ed. São Paulo: Saraiva, 2015. 